\title{
Do High Dose Progesterone Levels Affect Clinical Pregnancy Rates in Freeze-All Cycles?
}

(D) Volkan TURANa,

- Murat SÖNMEZER ${ }^{b}$

aMemorial Service Hospital,

İstanbul, TURKEY

${ }^{\mathrm{b} D e p a r t m e n t}$ of Obstetrics and Gynecology, Ankara University Faculty of Medicine, Ankara, TURKEY

Received: 04 Sep 2019

Accepted: 06 Sep 2019

Available online: 22 Oct 2019

Correspondence:

Murat SÖNMEZER

Ankara University Faculty of Medicine,

Department of Obstetrics and Gynecology,

Ankara, TURKEY

msonmezer@gmail.com

An editorial commentary entitled

"Do high dose progesterone levels affect

clinical pregnancy rates

in freeze-all cycles?" and attributed

to the article numbered

DOI: $10.5336 /$ jcog.2019-66058
Copyright (C) 2019 by Türkiye Klinikleri
$\mathrm{P}$ rogesterone is the primary hormone secreted during the luteal phase of the menstrual cycle, which makes endometrium receptive to implantation of an embryo. The elevation of serum progesterone due to premature luteinization (PL) before ovulation trigger is generally prevented by suppressing luteinizing hormone secretion with a gonadotropin-releasing hormone agonist or antagonist during controlled ovarian hyperstimulation. However, despite these treatments, high serum progesterone levels can still be observed on the day of ovulation trigger probably due to high dose gonadotropins and may shift the endometrial window of receptivity. ${ }^{1}$ Elevated late follicular phase progesterone levels are usually defined as the serum progesterone levels of $\geq 1.5 \mathrm{ng} / \mathrm{L}$ on the day of ovulation trigger. In previous studies, it was reported that the incidence of premature luteinization varies from $10 \%$ to $40 \%$ during the stimulated in vitro fertilization cycles (IVF). ${ }^{2}$

The effect of progesterone elevation on the day of human chorionic gonadotropin (hCG) administration in pregnancy outcomes during in vitro fertilization/intracytoplasmic sperm injection cycles is still controversial. Although many studies demonstrated a negative effect of PL on pregnancy outcome when the progesterone level was $>1.5 \mathrm{ng} / \mathrm{mL}$ on the day of ovulation trigger, others found no relationship between elevated progesterone levels and clinical pregnancy rate in fresh IVF cycles. ${ }^{3-5}$ In a recent metaanalysis, when a multivariable analysis was performed, controlling for the effect of the confounders such as female age, number of oocytes retrieved, number of embryos transferred, developmental stage of embryos at transfer, the woman's body mass index, the total dose of FSH administered during ovarian stimulation, and the type of gonadotropin-releasing hormone analogs used, live birth rates (Odds ratio: 0.68, 95\% CI: 0.48-0.97) were significantly decreased in the group with PL on the day of hCG. ${ }^{6}$ The number of oocytes retrieved was found to be the most potent confounder, causing a $29.4 \%$ reduction in the odds ratio for live birth. However, it is unclear whether progesterone elevation itself has a detrimental effect on IVF outcome, or it is just a reflection of an inappropriate ovarian stimulation leading to an asynchrony between endometrium and embryo. 
Since frozen-thawed embryo transfer requires no ovarian stimulation, it provides the opportunity to avoid the assumed negative effects of supraphysiological estrogen and progesterone levels. In a study by Groenewoud et al., it was reported that elevated progesterone levels in patients undergoing modified natural cycle frozen-thawed embryo transfer do not seem to have an effect on live birth and pregnancy rates. ${ }^{7}$ In concordance with this study, the present one found clinically nonsignifi- cant effects of early progesterone elevation on pregnancy outcomes in hormone replacement therapy assisted frozen-thawed cycles despite small sample size. ${ }^{8}$ It can, therefore, be questioned whether elevated progesterone is the only factor affecting pregnancy outcomes or more complex endocrine disorder following ovarian stimulation plays a role. In the future, further randomized controlled studies with larger sample size will help us draw more precise and accurate conclusions.
1. Sönmezer M, Pelin Cil A, Atabekoğlu C, Ozkavukçu S, Ozmen B. Does premature luteinization or early surge of LH impair cycle outcome? Report of two successful outcomes. J Assist Reprod Genet. 2009;26(2-3):159-63. [Crossref] [PubMed] [PMC]

2. Huang R, Fang C, Xu S, Yi Y, Liang X. Premature progesterone rise negatively correlated with live birth rate in IVF cycles with $\mathrm{GnRH}$ agonist: an analysis of 2,566 cycles. Fertil Steril. 2012;98(3):664-70.e2. [Crossref] [PubMed]

3. Schoolcraft W, Sinton E, Schlenker T, Huynh D, Hamilton F, Meldrum DR. Lower pregnancy rate with premature luteinization during pituitary suppression with leuprolide acetate. Fer-

\section{REFERENCES}

til Steril. 1991;55(3):563-6. [Crossref] [PubMed]

4. Saleh HA, Omran MS, Draz M. Does subtle progesterone rise on the day of HCG affect pregnancy rate in long agonist ICSI cycles? J Assist Reprod Genet. 2009;26(5):239-42. [Crossref] [PubMed] [PMC]

5. Urman B, Alatas C, Aksoy S, Mercan R, Isiklar $A$, Balaban B. Elevated serum progesterone level on the day of human chorionic gonadotropin administration does not adversely affect implantation rates after intracytoplasmic sperm injection and embryo transfer. Fertil Steril. 1999;72(6):975-9. [Crossref] [PubMed]

6. Venetis CA, Kolibianakis EM, Bosdou JK, Lainas GT, Sfontouris IA, Tarlatzis BC, et al.
Estimating the net effect of progesterone elevation on the day of hCG on live birth rates after IVF: a cohort analysis of 3296 IVF cycles. Hum Reprod. 2015;30(3):684-91. [Crossref] [PubMed]

7. Groenewoud ER, Macklon NS, Cohlen BJ; ANTARCTICA Study Group. The effect of elevated progesterone levels before HCG triggering in modified natural cycle frozenthawed embryo transfer cycles. Reprod Biomed Online. 2017;34(5):546-54. [Crossref] [PubMed]

8. Ozdemir AZ, Gülümser Ç, Türkmen A, Karlı P, Güven D. Do high dose progesterone levels affect clinical pregnancy rates in freeze-all cycles? JCOG. [Link] 